\title{
Resuming Work After Cancer: A Prospective Study of Occupational Register Data
}

\author{
C. A. M. Roelen • P. C. Koopmans • \\ A. J. M. Schellart • A. J. van der Beek
}

Published online: 14 December 2010

(C) The Author(s) 2010. This article is published with open access at Springerlink.com

\begin{abstract}
Introduction Long-term employment rates have been studied in cancer survivors, but little is known about the return to work of cancer patients. This study investigated return to work (RTW) within 2 years after the diagnosis of different types of cancer. Methods This prospective study investigated the associations of demographics (age, gender, socioeconomic status, and residential region) and occupational factors (occupation, duration of employment, and company size) of employees absent from work due to cancer with the time to partial RTW, defined as working at least $50 \%$ of the earnings before sickness absence. Likewise, the associations of demographics and occupational factors with full RTW at equal earnings as before sickness absence were investigated. Results The cohort included 5,234 employees who had been absent from work due to cancer between January 2004 and December 2006. The time to partial RTW was shortest among employees with skin cancer (median 55 days) and longest among employees
\end{abstract}

C. A. M. Roelen - A. J. M. Schellart - A. J. van der Beek Department of Public and Occupational Health, EMGO+ Institute for Health and Care Research,

VU University Medical Center, Van der Boechorststraat 7, 1081 BT Amsterdam, The Netherlands

C. A. M. Roelen ( $\square)$

ArboNed Corporate Accounts Zwolle,

PO Box 158, 8000 AD Zwolle, The Netherlands

e-mail: corne.roelen@arboned.nl

P. C. Koopmans

ArboNed Statistics, PO Box 141, 9700 AC Groningen,

The Netherlands

A. J. M. Schellart · A. J. van der Beek

Research Center for Insurance Medicine AMC-UMCG-UWV-

VU University Medical Center, Van der Boechorststraat 7,

1081 BT Amsterdam, The Netherlands with lung cancer (median 377 days). There were no significant associations between RTW and demographics. With regard to the occupational factors, employees in high occupational classes started working earlier than those in low occupational classes, but the time to full RTW did not differ significantly across occupational classes. Employees working in large companies returned to work earlier than those working in small companies. Conclusion RTW after different types of cancer depended on occupational factors rather than demographics.

Keywords Cancer - Sick leave - Return to work · Parametric survival analysis

\section{Introduction}

In The Netherlands, more than 33,000 gainfully employed men and women were newly diagnosed with cancer in 2006. Recent improvements in screening and treatment have not only increased cancer survivorship [1], but also the ability of employees to resume their work after cancer [2-4]. Return to work after cancer can be regarded as social recovery and adds to the survivors' quality of life.

Recent studies on the employment of cancer survivors have focused on employment rates three to 20 years after diagnosis based on national employment statistics $[2,5]$. Overall, cancer survivors were 1.4 times more likely to be unemployed on the long-term than healthy controls [6]. Three years after diagnosis, the employment rate of Finnish cancer survivors was $71 \%$ (range 41-84\%) and varied considerably per cancer type [7, 8]. A 20-year follow-up study showed that $19 \%$ of 65,510 Danish cancer patients were unemployed after a mean duration of 5.2 years [9]. Employment rates of 34,032 Norwegians diagnosed with 
cancer between 1953 and 2001 showed that $13 \%$ of male cancer survivors and $20 \%$ of female cancer survivors were not employed in 2001 as compared to $8 \%$ of male controls and $14 \%$ of female controls [10]. The employment rate of cancer survivors has most commonly been found to be associated with age, cancer type and treatment, education, occupation, and work load [7].

Employees encounter considerable problems when they resume work after cancer [11, 12]. Apart from the physical limitations, difficulties in managing fatigue and coping with the stress of having had cancer interfere with return to work [13]. Furthermore, a non-supportive work climate and the advice from physicians about work may postpone return to work [14]. Recently, Verbeek discussed three opportunities for physicians to help cancer patients resume their work [15]. The first opportunity is including the skills necessary for return to work in the patient's treatment [16]. Secondly, physicians may advise to accommodate the work environment, for instance by adjusting work tasks and times and by creating a supportive work environment to facilitate return to work [11]. Finally, occupational rehabilitation should pay attention to disability cognitions as it has been reported that $20 \%$ of cancer patients mentioned deterioration in work motivation and career prospects [12].

Few studies have examined the time to return to work after the diagnosis of cancer. Balak et al. [18] reported that women with early-stage breast cancer returned to work 4.7 (standard deviation $[\mathrm{SD}]=5.4$ ) months after surgery, 3.0 $(\mathrm{SD}=3.0)$ months after finishing adjuvant radiotherapy, and 5.5 ( $\mathrm{SD}=3.2$ ) months after finishing adjuvant chemotherapy [18]. The present study investigates the time to return to work for other cancer types within 2 years after diagnosis. We were interested in the associations of demographics (age, gender, socioeconomic status, and residential region) and occupational factors (occupation, duration of employment, and company size) with the time to partial return to work as well as full return to work.

\section{Methods}

\section{Study Population and Setting}

ArboNed Occupational Health Services contracts Dutch companies nationwide to provide their employees with occupational health services. ArboNed collects information about the employees from the Human Resources departments of all contracted companies. The ArboNed register contains the sickness absence data and medical diagnoses of 1 million employees of whom $22 \%$ worked in the industrial sector and $78 \%$ in the service sector. According to Statistics Netherlands, $23 \%$ of the Dutch workforce was employed in the industrial sector and $73 \%$ in the service sector in 2005 [19].

In The Netherlands, employees report sick to their employer. The employer records sickness absence and sends the sick report electronically to the ArboNed register on the first day of sickness absence. Short-term sickness absence is self-certified, but sickness absence episodes exceeding 4 weeks must be medically certified by an occupational physician (OP) with diagnoses of the 10th version of the International Classification of Diseases [20].

\section{Sickness Absence Register Data}

The ArboNed sickness absence register included 1,091,578 employees in 2004, 1,010,686 employees in 2005, and 1,024,100 employees in 2006 working in more than 30,000 different companies. Employees with sickness absence due to breast cancer, genital cancer, gastrointestinal cancer, lung cancer, skin cancer, or blood malignancies were eligible for this study if they were:

- absent from work due to cancer between 1 January 2004 and 31 December 2006

- in paid permanent employment at the time of diagnosis.

If an employee had more than one episode of sickness absence due to cancer between January 2004 and December 2006, only the first episode was included in the study, even if the second episode was due to another type of cancer. Hence, all episodes were independent observations. The time to full return to work after cancer was compared to the time to full return to work of 271,834 sickness absences due to non-malignant disorders, mostly chronic musculoskeletal disorders $(38 \%)$, mental disorders $(20 \%)$, gastrointestinal disorders $(5 \%)$, and respiratory disorders (5\%). All employees gave informed consent to the use of their sickness absence data for scientific research. According to Dutch law, approval from a medical ethics committee was not necessary as we analyzed sickness absence register data and neither consulted medical files nor involved the employees personally in the study.

\section{Demographics and Occupational Factors}

Age ( $<35$ years, 35-44 years, 45-54 years, and $\geq 55$ years) at the time of diagnosis, gender (male, female), socioeconomic status, and residential region were retrieved from the sickness absence register and included as demographic independent variables. The socioeconomic status and residential region were determined by the employees' zipcodes, which were recoded into neighbourhood socioeconomic status estimations according to the guidelines of the Netherlands Institute for Social Research [21]. The residential regions were divided into a western region (zipcodes 
1,000-2,999), central region (zipcodes 3,000-3,999), southern region (zipcodes 4,000-5,999), eastern region (zipcodes 6,000-7,999), and a northern region (zipcodes 8,000-9,999).

Occupation, duration of employment $(0-5$ years, 6-10 years, 10-20 years, and $>20$ years $)$, and company size $(<75$, $75-500,501-5,000$, and $>5,000$ staff) were included as occupational independent variables. Occupations were categorized using the SBC-1992 (2001 modified version) program of Statistics Netherlands [22], which is based on the International Standard Classification of Occupations (ISCO-88) issued by the International Labour Office [23]. The SBC-1992 classification distinguishes between low (primary school and junior occupational education), medium (senior occupational education), and high (high school and university) occupational classes, as well as types of occupations (unskilled workers, technicians, operators, transporters, teachers, care takers, administrators, sales workers, and managers).

\section{Events: Partial and Full Return to Work}

The calendar days between the date of reporting sick and date of return to work (RTW) were regarded as days of sickness absence irrespective of the actual work days. Dutch sickness absence insurance legislation regards episodes of sickness absence as one episode when they have less than 28 days of recovery between them, even if the causes of the episodes differ. We adopted this insurance time frame of 28 days in our definitions of RTW. Partial RTW was defined as working at $\geq 50 \%$ of the earnings before sickness absence for at least 28 consecutive days. Full RTW was defined as working at equal earnings as before sickness absence for at least 28 consecutive days. Data were censored if RTW did not occur within 2 years after diagnosis and if employees left employment $(n=446)$ or died $(n=324)$ within 2 years after diagnosis.

\section{Statistics}

Cox proportional hazards models are widely used to analyse survival data. Although a time-dependence parameter can be imposed in Cox models, parametric models are preferred when time itself is an independent variable [24]. Time plays an important role in RTW, as the probability of resuming work decreases with increasing duration of sickness absence [25, 26]. Different types of parametric models can be distinguished, based on the time dependence of the hazard that is the probability of the event occurring $[27,28]$. The hazard function reflects the baseline hazard for an average individual in the sample at any moment in time. The generalized gamma (GG) distribution is a threeparameter hazard function with location parameter $(\gamma)$, scale parameter $(\delta)$, and shape parameter $(\kappa)$. The GG distribution over time $(\mathrm{t})$ is given by the probability density function:

$f_{G G}(t)=\frac{|\delta| \gamma(\gamma t)^{\kappa \delta-1} \exp \left[-(\gamma t)^{\delta}\right]}{\Gamma(\kappa)}$

in which $\Gamma$ denotes the gamma function $\Gamma=\int_{0}^{\infty} x^{\kappa-1} \varepsilon^{-x} d x$ [29, 30].

The GG distribution is convenient because it includes monotonically increasing or decreasing hazard functions, as well as bathtub-shaped or arc-shaped functions [28-32]. This advantage, however, is neutralized by the difficulties in estimating the GG parameters [31]. Lawless [32] recommended the Maximum Likelihood Method (MLM) to select arbitrary values of $\kappa$ and generate the maximum likelihood estimates of $\gamma$ and $\delta$ for any given $\kappa$ [32]. The optimal value of $\kappa$ is determined by comparing the likelihood ratios for alternative values of $\kappa$. Using the MLM strategy, we calculated a GG model with $\kappa=10$ for the baseline hazard function (Fig. 1a). In order to check the statistical fit of this parametric GG model, generalized residuals were computed [33]. The residuals follow a straight line in the residual plot if the GG model is appropriate (Fig. 1b).

Lawless also showed that the GG regression model can be written as: $\log (\mathrm{t})=\mathrm{b}_{0}+\mathrm{b}_{1} \mathrm{X}_{1}+\mathrm{b}_{2} \mathrm{X}_{2}+\ldots \ldots+$ $\mathrm{b}_{\mathrm{i}} \mathrm{X}_{\mathrm{i}}+\varepsilon^{\delta}$ [32] in which $\varepsilon$ is an error term and $\delta$ determines

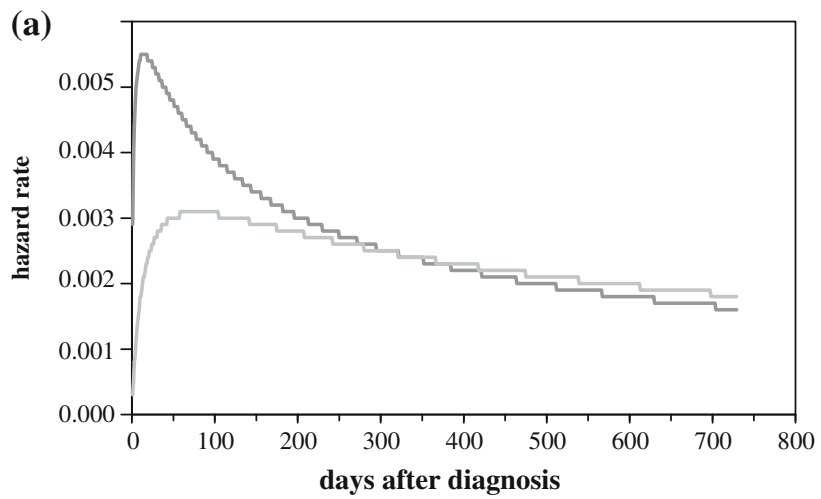

(b)

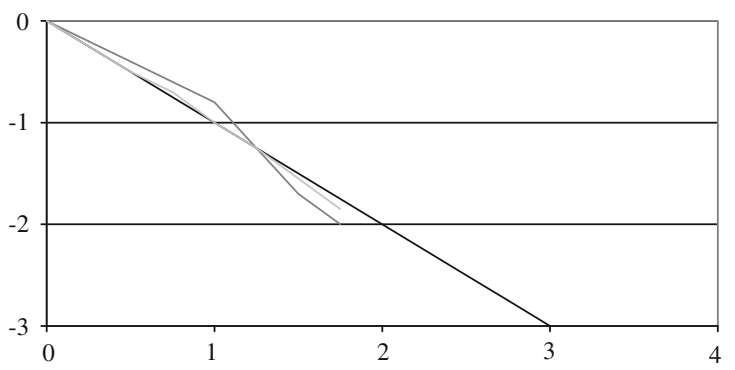

Fig. 1 a The hazard function over time for partial return to work (dark grey line) and full return to work (light grey line). b Residual plot showing the fit of the generalized gamma model for partial return to work (dark grey line) and full return to work (light grey line) 
the error variance. The GG regression model estimates the GG regression coefficients $\left(b_{\mathrm{GG}}\right) b_{1}$ to $b_{i}$. If $a b_{G G}$ is negative then an increase in the corresponding variable shortens the expected duration until the occurrence of RTW, whereas it has the opposite effect when the $b_{\mathrm{GG}}$ is positive [34]. All analyses were performed in Transition Data Analysis (TDA, version 6.40), which is the preferred software for parametric survival models [24, 35], controlling for type of cancer, demographics and occupational variables. Lack of independence or clustering could be produced by subjects being categorized by a common factor and this might result in decreased standard errors. To prevent wrongly rejecting the null hypothesis, the level of significance was set at $1 \%$ and significance was concluded for $P<0.01$.

\section{Results}

Between January 2004 and December 2006, 5,234 employees had an episode of sickness absence due to cancer and were eligible for this study. Breast cancer, female genital cancer, and gastrointestinal cancer were most prevalent as is shown in Table $1.65 \%$ of employees with cancer were $\geq 45$ years of age, $57 \%$ worked in low occupational classes, and $30 \%$ in administration or sales. The greater part of employees with cancer worked $<10$ years in companies employing $<500$ workers. Followup was incomplete in 770 employees $(15 \%)$.

The RTW curves per cancer type showed that RTW of employees after skin cancer and genital cancer was comparable to RTW after non-malignant chronic disease (Fig. 2). For other types of cancer the RTW rates were lower than for non-malignant chronic disease.

The data of 2,050 employees with cancer were incomplete, mainly because of missings in the occupational independent variables. The employees with incomplete data did not differ in age category (Chi-square $P=0.46$ ), gender (Chi-square $P=0.23$ ), or socioeconomic status (Chi-square $P=0.03$ ) from those with complete data, but employees living in the western region of The Netherlands more often had missing data (Chi-square $P<0.01$ ). 3,024 employees (58\%) with complete data were included in GG regression analysis.

\section{Partial Return to Work}

The time to partial RTW was longer among employees with breast cancer, gastrointestinal cancer, lung cancer and blood malignancies, and in men with genital cancer compared to employees with skin cancer (Table 2). The GG regression coefficients of female genital cancer did not differ significantly from the GG coefficients of skin cancer, indicating that the partial RTW of women after genital cancer approximated that of employees with skin cancer, which was also demonstrated in Fig. 2.

Although young employees ( $<35$ years of age) tended to resume work earlier (median 124 days after reporting sick) than employees aged $\geq 55$ years (median 218 days), the difference $(P=0.08)$ was not significant at the $1 \%$ level. The time to partial RTW after cancer did not depend on gender and did not differ across socioeconomic classes or residential regions (Table 2).

Employees working in high occupational classes resumed work earlier than those working in low occupational classes. Transporters, administrators and sales workers, and managers started working earlier than unskilled workers, but the differences in partial RTW after cancer were not significant between occupations (Table 2). Finally, employees working in companies staffing $>5,000$ people started working earlier (median 113 days) than those working in companies staffing $<75$ people (median 217 days).

\section{Full Return to Work}

The associations of cancer type with full RTW were similar to those with partial RTW. Employees aged $<35$ years fully resumed work earlier (median 181 days) than those aged $\geq 55$ years (median 293 days), but, as with partial RTW, the difference $(P=0.03)$ was not significant at the $1 \%$ level. Employees with cancer living in the central region of The Netherlands had full RTW earlier than those living in the western provinces. The other demographics were not associated with the time to full RTW.

In contrast to partial RTW, the occupational class was not significantly associated with the time to full RTW. Employees working in the public sector were likely to fully resume work later than those working in the private sector, but occupations were not significantly associated with the time to full RTW. Employees working 6-10 years for a company fully resumed work later than those working in a company for 0-5 years. Employees working in large companies staffing $>5,000$ people fully returned to work earlier (median time 180 days) than those working in small companies staffing $<75$ people (median time 313 days).

\section{Discussion}

In this study, the time to partial and full RTW after cancer was assessed using parametric generalized gamma models for survival data, which account for changes in the hazard over time. RTW after cancer depended on the type of cancer and occupational factors. Employees working in high occupational classes resumed work earlier than those in low occupational classes, whereas the time to full RTW 


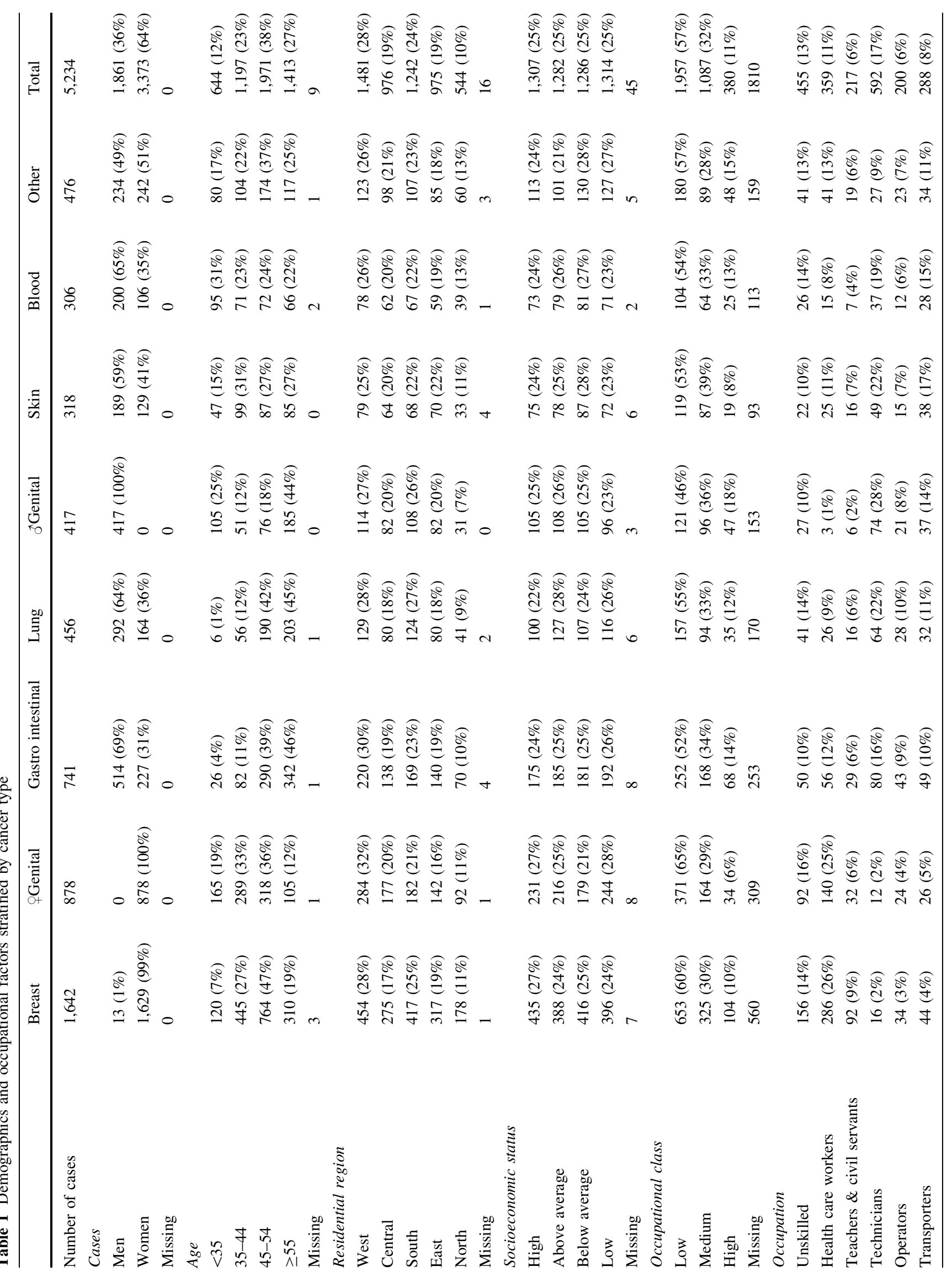



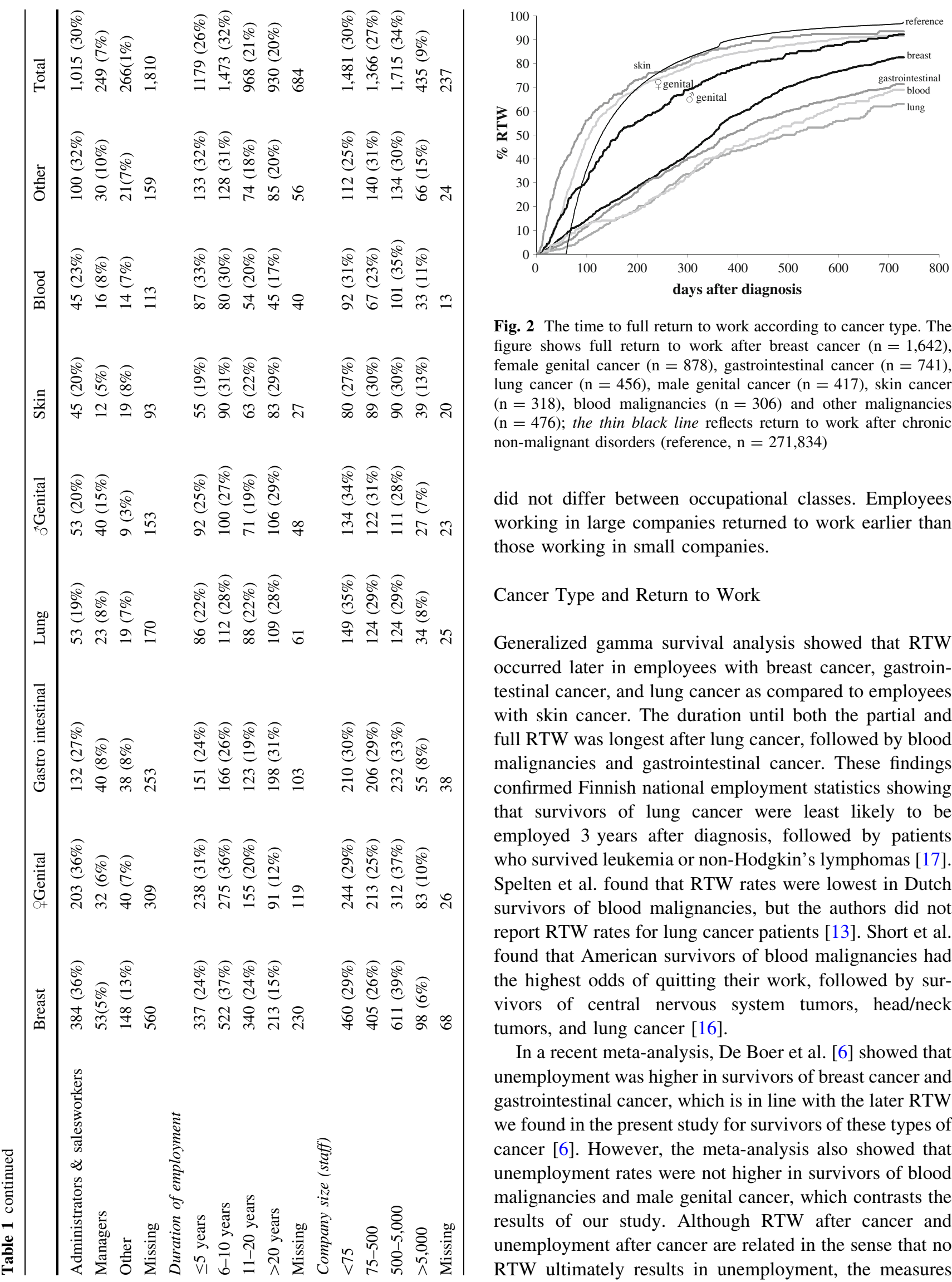

Fig. 2 The time to full return to work according to cancer type. The figure shows full return to work after breast cancer $(n=1,642)$, female genital cancer $(n=878)$, gastrointestinal cancer $(n=741)$, lung cancer $(\mathrm{n}=456)$, male genital cancer $(\mathrm{n}=417)$, skin cancer $(\mathrm{n}=318)$, blood malignancies $(\mathrm{n}=306)$ and other malignancies $(\mathrm{n}=476)$; the thin black line reflects return to work after chronic non-malignant disorders (reference, $\mathrm{n}=271,834$ )

did not differ between occupational classes. Employees working in large companies returned to work earlier than those working in small companies.

\section{Cancer Type and Return to Work}

Generalized gamma survival analysis showed that RTW occurred later in employees with breast cancer, gastrointestinal cancer, and lung cancer as compared to employees with skin cancer. The duration until both the partial and full RTW was longest after lung cancer, followed by blood malignancies and gastrointestinal cancer. These findings confirmed Finnish national employment statistics showing that survivors of lung cancer were least likely to be employed 3 years after diagnosis, followed by patients who survived leukemia or non-Hodgkin's lymphomas [17]. Spelten et al. found that RTW rates were lowest in Dutch survivors of blood malignancies, but the authors did not report RTW rates for lung cancer patients [13]. Short et al. found that American survivors of blood malignancies had the highest odds of quitting their work, followed by survivors of central nervous system tumors, head/neck tumors, and lung cancer [16].

In a recent meta-analysis, De Boer et al. [6] showed that unemployment was higher in survivors of breast cancer and gastrointestinal cancer, which is in line with the later RTW we found in the present study for survivors of these types of cancer [6]. However, the meta-analysis also showed that unemployment rates were not higher in survivors of blood malignancies and male genital cancer, which contrasts the results of our study. Although RTW after cancer and unemployment after cancer are related in the sense that no RTW ultimately results in unemployment, the measures 
Table 2 Survival analysis of return to work stratified by cancer type using a generalized gamma parametric model

\begin{tabular}{|c|c|c|c|c|}
\hline & \multicolumn{2}{|c|}{ Time to partial return to work } & \multicolumn{2}{|l|}{ Time to full return to work } \\
\hline & Median days $\left(99 \% \mathrm{CI}^{\mathrm{a}}\right)$ & $\mathrm{b}_{\mathrm{GG}}^{\mathrm{b}}\left(99 \% \mathrm{CI}^{\mathrm{a}}\right)$ & Median days $\left(99 \% \mathrm{CI}^{\mathrm{a}}\right)$ & $\mathrm{b}_{\mathrm{GG}}^{\mathrm{b}}\left(99 \% \mathrm{CI}^{\mathrm{a}}\right)$ \\
\hline \multicolumn{5}{|l|}{ Cancer type } \\
\hline Skin & $51(35-67)$ & Reference & $75(45-105)$ & Reference \\
\hline Breast & $271(246-296)$ & $1.06(0.76-1.37)^{* *}$ & $349(329-369)$ & $1.08(0.84-1.33) * *$ \\
\hline †Genital & $79(68-90)$ & $0.26(-0.06$ to 0.58$)$ & $104(90-118)$ & $0.22(-0.04$ to 0.48$)$ \\
\hline Gastrointestinal & 249 (201-297) & $1.35(1.03-1.66)^{* *}$ & $344(291-397)$ & $1.31(1.05-1.56)^{* *}$ \\
\hline Lung & $377(307-447)$ & $1.88(1.51-2.25)^{* *}$ & $484(351-617)$ & $1.61(1.31-1.92)^{* *}$ \\
\hline ¿Genital & $112(87-137)$ & $0.63(0.27-0.98)^{* *}$ & $164(116-212)$ & $0.71(0.43-1.00)^{* *}$ \\
\hline Blood & $299(236-362)$ & $1.56(1.17-1.94)^{* *}$ & $392(302-482)$ & $1.50(1.19-1.81)^{* *}$ \\
\hline Other & $222(174-270)$ & $1.19(0.85-1.53)^{* *}$ & $297(219-375)$ & $1.08(0.81-1.36)^{* *}$ \\
\hline \multicolumn{5}{|l|}{ Demographics } \\
\hline \multicolumn{5}{|l|}{ Age } \\
\hline$\geq 55$ years & $218(192-244)$ & Reference & $293(260-326)$ & Reference \\
\hline $45-54$ years & $206(180-232)$ & $-0.07(-0.24$ to 0.10$)$ & $288(256-320)$ & $-0.02(-0.16$ to 0.12$)$ \\
\hline $35-44$ years & $165(127-203)$ & $-0.11(-0.30$ to 0.09$)$ & 259 (221-297) & $-0.07(-0.24$ to 0.09$)$ \\
\hline$<35$ years & $124(90-158)$ & $-0.17(-0.42$ to 0.08$)$ & $181(127-235)$ & $-0.16(-0.37$ to 0.04$)$ \\
\hline \multicolumn{5}{|l|}{ Gender } \\
\hline Men & $193(170-216)$ & Reference & $272(242-302)$ & Reference \\
\hline Women & $200(177-223)$ & $0.20(-0.03$ to 0.43$)$ & 273 (249-297) & $0.13(-0.06$ to 0.32$)$ \\
\hline \multicolumn{5}{|l|}{ Socioeconomic status } \\
\hline Low & $200(168-232)$ & Reference & $275(239-311)$ & Reference \\
\hline Below average & $201(166-236)$ & $0.01(-0.19$ to 0.20$)$ & $272(234-310)$ & $0.02(-0.13$ to 0.18$)$ \\
\hline Above average & $198(165-231)$ & $-0.05(-0.23$ to 0.14$)$ & $277(244-310)$ & $-0.01(-0.16$ to 0.14$)$ \\
\hline High & $189(158-220)$ & $-0.04(-0.24$ to 0.15$)$ & $270(229-311)$ & $0.00(-0.16$ to 0.16$)$ \\
\hline \multicolumn{5}{|l|}{ Residential region } \\
\hline West & $197(164-230)$ & Reference & $293(252-334)$ & Reference \\
\hline Central & $180(144-216)$ & $-0.12(-0.32$ to 0.07$)$ & $257(206-308)$ & $-0.16(-0.32 \text { to }-0.00)^{* *}$ \\
\hline South & $190(161-219)$ & $-0.01(-0.20$ to 0.18$)$ & $268(231-305)$ & $-0.11(-0.26$ to 0.04$)$ \\
\hline East & $205(158-252)$ & $-0.00(-0.20$ to 0.20$)$ & 257 (217-297) & $-0.16(-0.32$ to 0.01$)$ \\
\hline North & $232(196-268)$ & $0.06(-0.18$ to 0.30$)$ & $298(253-343)$ & $-0.05(-0.24$ to 0.15$)$ \\
\hline \multicolumn{5}{|l|}{ Occupational factors } \\
\hline \multicolumn{5}{|l|}{ Occupational class } \\
\hline Low & $199(176-222)$ & Reference & $265(240-290)$ & Reference \\
\hline Medium & $195(168-222)$ & $-0.14(-0.32$ to 0.03$)$ & $286(254-318)$ & $0.03(-0.11$ to 0.17$)$ \\
\hline High & $183(137-229)$ & $-0.31(-0.57 \text { to }-0.04)^{* *}$ & $275(228-322)$ & $-0.03(-0.25$ to 0.19$)$ \\
\hline \multicolumn{5}{|l|}{ Occupation } \\
\hline Unskilled & $219(171-267)$ & Reference & $287(220-354)$ & Reference \\
\hline \multicolumn{5}{|l|}{ Public sector } \\
\hline Health care workers & $204(160-248)$ & $-0.01(-0.27$ to 0.24$)$ & $283(231-335)$ & $-0.07(-0.27$ to 0.14$)$ \\
\hline Teachers and civil servants & $260(200-320)$ & $0.12(-0.24$ to 0.48$)$ & $326(269-383)$ & $-0.01(-0.31$ to 0.28$)$ \\
\hline \multicolumn{5}{|l|}{ Private sector } \\
\hline Technicians & $190(148-232)$ & $-0.02(-0.33$ to 0.29$)$ & $279(206-352)$ & $-0.08(-0.34$ to 0.17$)$ \\
\hline Operators & $197(129-265)$ & $-0.21(-0.55$ to 0.14$)$ & $254(177-331)$ & $-0.15(-0.43$ to 0.13$)$ \\
\hline Transporters & $188(131-245)$ & $-0.06(-0.38$ to 0.26$)$ & $247(213-281)$ & $0.01(-0.25$ to 0.28$)$ \\
\hline Administrators \& salesworkers & $177(148-206)$ & -0.21 ( -0.43 to 0.02$)$ & $272(239-305)$ & $-0.08(-0.27$ to 0.10$)$ \\
\hline Managers & $154(90-218)$ & $-0.18(-0.53$ to 0.18$)$ & $248(206-290)$ & $-0.06(-0.35$ to 0.24$)$ \\
\hline Other & $162(64-260)$ & $-0.24(-0.83$ to 0.36$)$ & $273(73-473)$ & $-0.19(-0.67$ to 0.30$)$ \\
\hline
\end{tabular}


Table 2 continued

\begin{tabular}{|c|c|c|c|c|}
\hline & \multicolumn{2}{|c|}{ Time to partial return to work } & \multicolumn{2}{|l|}{ Time to full return to work } \\
\hline & Median days $\left(99 \% \mathrm{CI}^{\mathrm{a}}\right)$ & $\mathrm{b}_{\mathrm{GG}}^{\mathrm{b}}\left(99 \% \mathrm{CI}^{\mathrm{a}}\right)$ & Median days $\left(99 \% \mathrm{CI}^{\mathrm{a}}\right)$ & $\mathrm{b}_{\mathrm{GG}}^{\mathrm{b}}\left(99 \% \mathrm{CI}^{\mathrm{a}}\right)$ \\
\hline \multicolumn{5}{|c|}{ Duration of employment (years) } \\
\hline $0-5$ & $160(130-190)$ & Reference & $221(183-259)$ & Reference \\
\hline $6-10$ & $214(186-242)$ & $0.11(-0.06$ to 0.29$)$ & $294(263-325)$ & $0.18(0.04-0.33)^{* *}$ \\
\hline $11-20$ & $210(171-249)$ & $0.10(-0.09$ to 0.30$)$ & $292(258-326)$ & $0.12(-0.04$ to 0.28$)$ \\
\hline$>20$ & $197(167-227)$ & $0.00(-0.20$ to 0.21$)$ & $259(226-292)$ & $0.03(-0.14$ to 0.20$)$ \\
\hline \multicolumn{5}{|l|}{ Company size } \\
\hline$<75$ & $217(173-261)$ & Reference & $313(273-353)$ & Reference \\
\hline $75-500$ & $203(174-232)$ & $-0.10(-0.28$ to 0.08$)$ & $275(243-307)$ & $-0.11(-0.26$ to 0.04$)$ \\
\hline $500-5,000$ & $197(172-222)$ & $-0.13(-0.31$ to 0.05$)$ & $272(240-304)$ & $-0.10(-0.25$ to 0.05$)$ \\
\hline$>5,000$ & $113(74-152)$ & $-0.56(-0.82 \text { to }-0.29)^{* *}$ & $180(127-233)$ & $-0.54(-0.76 \text { to }-0.33)^{* *}$ \\
\hline
\end{tabular}

differ in time frame and context. RTW often takes places within the context of sickness absence and disability policies, whereas unemployment was assessed three to 20 years after diagnosis in most studies and depends on the social security policies of a country.

\section{The Association of Demographics with Return to Work} of Cancer Survivors

Age was not significantly associated with RTW after cancer at the $1 \%$ significance level, which corroborated the results of the aforementioned meta-analysis in which it was reported that the age of cancer survivors was not a prognostic risk factor for future unemployment [6]. Our results added that there were no gender differences in partial RTW and full RTW after cancer.

Neither the time to partial RTW nor the time to full RTW was associated with the socioeconomic status, indicating that people living in poor neighbourhoods did not resume work later than those living in wealthy neighbourhoods. Earlier studies have reported that a low socioeconomic status was related to a reduced likelihood of resuming work after cancer [36, 37]. However, a proper comparison is unfeasible because we used a contextual proxy to estimate the socioeconomic status instead of a family [36] or individual [37] measure.

The Association of Occupational Factors with Return to Work of Cancer Survivors

A review of 18 studies concerning the need for further research in cancer and work was published in 2004 [38]. In recent years, there has been increased interest in factors that may be related to cancer survivors' disability or decreased ability to work. Physical workload and heavy lifting have been associated with higher unemployment rates [13, 38-43]. Also, employees working in blue collar occupations were more likely to be unemployed than those working in white collar occupations [36, 42]. Our results showed that employees in high occupational classes started working earlier than employees working in low occupational classes. This confirms the finding that cancer survivors with low educational levels were less likely to be employed than age- and gender-matched healthy referents [40]. Lower class jobs are more likely to be physically straining and maybe work tasks and working hours can be more easily adjusted in high class jobs.

Taskila and colleagues reported that cancer survivors working in agricultural work, forestry and fishery, transport and communication, and manufacturing had an 18-20\% lower probability of being employed 3 years after diagnosis than age-matched employees without cancer [41]. The median time to full RTW in our study was shorter, though not significantly, among transporters (247 days) and operators (254 days) compared to unskilled workers (287 days). It may be possible that transporters and operators resume work initially, but quit their work on a later moment, for instance because of the physical workload or because they can not keep pace with colleagues [39, 42]. Alternatively, a worker may continue working in the same occupation, but under different working conditions. In this regard, it should be acknowledged that not only the content of occupations defined in this study may differ from the occupations classified by Taskila et al. [41], but also the working conditions. For example, employees working in Dutch manufacturing 
industry were mostly machine-operators and therefore less exposed to physical workloads.

Our results showed that RTW of cancer survivors was associated with the company size rather than occupation. Cancer survivors working in large companies started working earlier and had full RTW earlier than those working in small companies. We assume this is due to the fact that it is easier in large companies to accommodate work tasks and working hours to the work ability and vulnerability of cancer survivors. Furthermore, cancer survivors who were employed for 6-10 years fully returned to work later than those who were employed $\leq 5$ years. Cancer survivors who are employed $\leq 5$ years may be younger than those employed for many years, and young cancer survivors had earlier full RTW than those aged $\geq 55$ years. Alternatively, employees working for a company $\leq 5$ years may be more anxious to lose their job when sickness absence lasts too long.

\section{Strengths and Limitations of the Study}

The strength of our study is that we retrieved sickness absence register data of approximately 1 million workers, who were representative of the Dutch workforce. Sickness absence legislation and policies in The Netherlands did not change between January 2004 and December 2008. The diagnoses on the sickness absence certificates were not tested. However, there is hardly any doubt that occupational physicians write cancer as diagnosis on the sickness certificates of employees who do not have cancer. The sickness absence certificates included only one medical diagnosis. Therefore, we had no knowledge about comorbidity, such as fatigue, distress and depressive symptoms that are frequently found in cancer survivors $[8,11]$ and interfere with RTW.

A disadvantage of using sickness absence register data is that these data are recorded for other than research purposes. Hence, we had no control over which data were recorded and how data were registered. The interpretation of results was hampered by the fact that it was not possible to 'dig deeper' into the data. Moreover, we had no access to the medical files of the employees, so information on the cancer stage (local, regional, or metastatic), type of treatment, and side effects or complications of treatment was not available. It has been recognised that the employment of cancer survivors depends strongly on the type, extent, and treatment of cancer [11, 16, 44]. Also, information about impairments in physical and mental work ability and adjustments in the working conditions (e.g. ergonomic work improvements, accommodated work tasks, reduced working hours, placement in another job) was not available while these factors obviously facilitate RTW after cancer.
We conclude that the time to partial and full RTW after cancer depended on the type of cancer and occupational factors. Occupational factors are modifiable, although the accommodation of work tasks or working hours will be more difficult in lower class occupations and in small companies. It will be interesting to investigate the work role functioning of employees who resumed work after cancer in order to monitor how cancer survivors manage residual symptoms, physical limitations, and changed psychological cognitions. Such research will provide keys and tools for a sustainable working life of cancer survivors.

Acknowledgments The authors wish to thank Dr. Ulrich Pötter $\mathrm{PhD}$ of the German Youth Institute (DJI), Department of Social Monitoring, München (Germany) for his advice about parametric models in TDA and for critically reviewing the methods section with regard to the generalized gamma model.

Open Access This article is distributed under the terms of the Creative Commons Attribution Noncommercial License which permits any noncommercial use, distribution, and reproduction in any medium, provided the original author(s) and source are credited.

\section{References}

1. Verdecchia A, Francisci S, Brenner H, et al. EUROCARE-4 Working Group. Recent cancer survival in Europe: a 2000-2 period analysis of EUROCARE-4 data. Lancet Oncol. 2007;8: 784-96.

2. Amir Z, Brocky J. Cancer survivorship and employment: epidemiology. Occup Med. 2009;59:373-7.

3. de Boer AGEM, Frings-Dresen MHW. Employment and the common cancers: return to work of cancer survivors. Occup Med. 2009;59:378-80.

4. Munir F, Yarker J, McDermott H. Employment and the common cancers: correlates of work ability during or following cancer treatment. Occup Med. 2009;59:381-9.

5. Wynn P. Employment and the common cancers: overview. Occup Med. 2009;59:369-72.

6. de Boer AGEM, Taskila T, Ojajärvi A, van Dijk FJH, Verbeek JHAM. Cancer survivors and unemployment: a meta-analysis and meta-regression. J Am Med Assoc. 2009;301:753-62.

7. Taskila-Åbandt T, Pukkala E, Martikainen R, Karjalainen A, Hietanen P. Employment status of Finnish cancer patients in 1997. Psychooncol. 2005;14:221-6.

8. Taskila T, Lindbohm ML. Factors affecting cancer survivors' employment and work ability. Acta Oncol. 2007;46:446-51.

9. Carlsen K, Oksbjerg-Dalton S, Diderichsen F, Johansen C. Risk for unemployment of cancer survivors: a Danish cohort study. Eur J Cancer. 2008;44:1866-74.

10. Syse A, Tretli S, Kravdal Ø. Cancer's impact on employment and earnings - a population-based study from Norway. J Cancer Surviv. 2008;2:149-58.

11. Spelten ER, Sprangers MAG, Verbeek JHAM. Factors reported to influence return to work of cancer survivors: a literature review. Pyschooncol. 2002;11:124-31.

12. Amir Z, Moran T, Walsh L, Iddenden R, Luker K. Return to paid work after cancer: a British experience. J Cancer Surviv. 2007;1: 129-36. 
13. Spelten ER, Verbeek JAHM, Uitterhoeve ALJ, et al. Cancer, fatigue and the return of patients to work-a prospective cohort study. Eur J Cancer. 2003;39:1562-7.

14. Pryce J, Munir F, Haslam C. Cancer survivorship and work: symptoms, supervisor response, co-worker disclosure and work adjustment. J Occup Rehabil. 2007;17:83-92.

15. Verbeek JH. How can doctors help their patients return to work? PLoS Med. 2006;3:312-5.

16. Short PF, Vasey JJ, Tunceli K. Employment pathways in a large cohort of adult cancer survivors. Cancer. 2005;103:1292-301.

17. Taskila T. Cancer survivors and work. Work-related problems and factors associated with their employment, work ability and social support from the work community. Helsinki: Finnish Institute of Occupational Health; 2007.

18. Balak F, Roelen CA, Koopmans PC, Ten Berge EE, Groothoff JW. Return to work after early-stage breast cancer: a cohort study into the effects of treatment and cancer related symptoms. J Occup Rehabil. 2008;18:267-72.

19. Statistics Netherlands. Available from: http://statline.cbs.nl/Stat Web.html.

20. World Health Organisation. International classification of diseases and related health problems: ICD-10. Geneva: WHO; 1994.

21. The Netherlands Institute for Social Research. Available from: http://www.scp.nl/onderzoek/statusscores/.

22. Statistics Netherlands. Available from: http://www.cbs.nl/nl-NL/ menu/methoden/classificaties/overzicht/sbc/default.htm.

23. International Labour Organization (ILO). International standard classification of occupations: ISCO-88. Geneva: ILO; 1990.

24. Blossfeld HP, Rohwer G. Techniques of event history modelling: new approaches to causal analysis. 2nd ed. Mahwah (NJ): Lawrence Erlbaum; 2002.

25. Crook J, Moldofsky $\mathrm{H}$. The probability of recovery and return to work from work disability as a function of time. Qual Life Res. 1994;3(suppl 1):97-109.

26. Christensen KB, Andersen PK, Smith-Hansen L, Nielsen ML, Kristensen TS. Analyzing sickness absence with statistical models for survival data. Scand J Work Environ Health. 2007;33: 233-9.

27. Koopmans PC, Roelen CA, Groothoff JW. Parametric hazard rate models for long-term sickness absence. Int Arch Occup Environ Health. 2009;82:575-82.

28. Box-Steffensmeier JM, Jones BS. Event history modelling: a guide for social scientists. Cambridge: Cambridge University Press; 2004.
29. Klein JP, Moeschberger ML. Survival analysis; techniques for censored and truncated data. Berlin: Springer; 1997.

30. Cox C, Chu H, Schneider MF, Muñoz A. Parametric survival analysis and taxonomy of hazard functions for the generalized gamma distribution. Stat Med. 2007;26:4352-74.

31. Gomes O, Combes B, Dussauchoy A. Parameter estimation of the generalized gamma distribution. Math Comp Sim. 2008;79: 955-63.

32. Lawless JF. Statistical models and methods for lifetime data. New York: Wiley-Interscience; 1982.

33. Cox DR, Snell EJ. A general definition of residuals. J Royal Stat Soc Series. 1968;B30:248-75.

34. Transition Data Analysis. Available from: http://www.stat.ruhruni-bochum.de/tda.html.

35. Bouknight RR, Bradley CJ, Luo Z. Correlates of return to work for breast cancer survivors. J Clin Oncol. 2006;24:345-53.

36. Drolet M, Maunsell E, Mondor M, Brisson C, Brisson J, Mâsse J, Dechênes L. Work absence after breast cancer diagnosis: a population-based study. CMAJ. 2005;173:765-71.

37. Steiner JF, Cavender TA, Main DS, Bradley CJ. Assessing the impact of cancer on work outcomes: what are the research needs? Cancer. 2004;101:1703-11.

38. Bradley CJ, Bednarek HL. Employment patterns of long-term cancer survivors. Pyschooncol. 2002;11:188-98.

39. Maunsell E, Drolet M, Brisson J, Brisson C, Mâsse J, Dechênes L. Work situation after breast cancer: results from a populationbased study. J Natl Cancer Inst. 2004;96:1813-22.

40. Taskila-Åbrandt T, Martikainen R, Virtanen SV, Pukkala E, Hietanen P, Lindbohm ML. The impact of education and occupation on the employment status of cancer survivors. Eur J Cancer. 2004;40:2488-93.

41. Bradley CJ, Neumark D, Luo Z, Bednarek H, Schenk M. Employment outcomes of men treated for prostate cancer. J Natl Cancer Inst. 2005;97:958-65.

42. Bednarek HL, Bradley CJ. Work and retirement after cancer diagnosis. Res Nurs Health. 2005;28:126-35.

43. Schultz P, Beck M, Stava C, Sellin R. Cancer survivors. Work related issues. Am J Occup Health Nurs. 2002;50:220-6.

44. Yabroff KR, Lawrence WF, Clauser S, Davis WW, Brown ML. Burden of illness in cancer survivors: findings from a populationbased national sample. J Natl Cancer Inst. 2004;96:1322-30. 